\title{
Numerical simulation of single- and double- faced $W$-beam guardrails under vehicular impacts on six-lane divided freeways
}

\author{
H. Fang ${ }^{1}$, N. Li ${ }^{1}$, M. Gutowski ${ }^{1}$, M. DiSogra ${ }^{1}$ \& D. C. Weggel ${ }^{2}$ \\ ${ }^{1}$ Department of Mechanical Engineering and Engineering Science, \\ The University of North Carolina at Charlotte, USA \\ ${ }^{2}$ Department of Civil and Environmental Engineering, \\ The University of North Carolina at Charlotte, USA
}

\begin{abstract}
W-beam guardrails are safety devices installed on highway medians to prevent cross-median crashes. For six-lane, 46-foot median divided freeways, the paved shoulder policy requires two 12-foot median shoulders, which reduce the width of median ditch to 22 feet. For positive pavement drainage consideration, the median slope should be changed to $4 \mathrm{H}: 1 \mathrm{~V}$, which exceeds the optimal $6 \mathrm{H}: 1 \mathrm{~V}$ slope for placing median barriers. As a practical solution, design engineers often place two lines of W-beam guardrails on the two median shoulders. While effectively preventing cross-median crashes, the two lines of guardrails create great difficulty for vegetation maintenance, e.g. mowing. There is a practical need to investigate the feasibility of replacing the two lines of single-faced guardrails with a single line of double-faced W-beam guardrail. In this study, nonlinear finite element (FE) analysis is utilized to evaluate the performance of single- and double-faced W-beam guardrails under vehicular impacts on a sixlane, 46-foot median divided freeway. Detailed FE models of the W-beam guardrails and the vehicle are presented. Various modelling issues involved in the nonlinear FE analysis such as contact modelling are discussed. Based on FE simulation results, a new double-faced W-beam guardrail is proposed and evaluated. The new design is shown to have improved performance over both the initial double-faced guardrail and the single-faced guardrail.

Keywords: finite element modelling, roadside safety, W-beam guardrail, sloped median, roadside safety, cross-median collisions.
\end{abstract}




\section{Introduction}

Median-involved crashes on high-speed, divided highways are predominately severe events in terms of injury severity, property damage, traffic impact, and the magnitude and duration of response required [1]. Median barriers can be used to effectively prevent vehicles leaving the roadway from crossing the median and colliding with vehicles traveling in the opposite direction. Despite the dramatic increase in traffic volumes, the fatal crash rate on US highways is only $20 \%$ of what it was 40 years ago. Part of the reason is attributed to the use of roadside barrier systems. Over the years, different types of barriers have been developed and are classified into three categories: rigid (e.g., concrete barriers), semi-rigid (e.g., W-beam guardrails), and flexible systems (e.g., cable barriers). While all barriers serve the purpose of safely redirecting errant vehicles and preventing them from intruding into the oncoming traffic, they differ from each other in applicable site conditions and in their effects on impacting vehicles.

W-beam guardrails are among the most commonly used barrier systems on US highways. Despite their generally good safety performance, research has shown their design weakness under large vehicle impacts, e.g., vehicle rollover due to snagging of the front wheel on the posts. In the study by Ross et al., the performance of longitudinal barriers placed on sloped terrain was investigated using both crash tests and computer simulations [2]. It was found from the study that W-beam and thrie-beam barriers were more sensitive to the effects of sloped terrain than cable barriers.

All safety barriers installed on US highways must be designed to conform to guidelines of the American Association of State Highway and Transportation Officials (AASHTO) [3] and satisfy the safety requirements specified by the Manual for Assessing Safety Hardware (MASH) [4], a replacement of the old highway safety standard, the NCHRP Report 350 [5]. It should be noted that the standard safety tests in MASH or NCHRP Report 350 are all conducted on flat terrain. Therefore, the safety performance of a barrier evaluated by the standard tests may not represent its true performance under in-service conditions.

Historically, the safety performance of roadside safety devices has been evaluated through full-scale crash testing. Physical crash testing is a valid means to examine the safety performance of barrier systems; however, it is very expensive, time-consuming, and difficult to perform under in-service conditions. With the rapid development of computing hardware and commercial software for high performance computing, computer simulations have been increasingly used in highway safety designs. Over the recent decades, various finite element (FE) models of vehicles and roadside safety devices have been developed and used in highway safety research [6-9].

In this study, nonlinear FE analysis is utilized to evaluate the performance of single- and double-faced W-beam guardrails under vehicular impacts on a sixlane, 46-foot median divided freeway. Detailed FE models of the W-beam guardrails and the vehicle are presented. Various modelling issues involved in the nonlinear FE analysis such as contact modelling are discussed. Based on FE simulation results, a new double-faced $\mathrm{W}$-beam guardrail is proposed and 
evaluated. The new design is shown to have improved performance over both the initial double-faced guardrail and the single-faced guardrail.

\section{Problem description}

Forty-six feet is the minimum median width of freeways unless concrete median barriers are used. For six-lane, 46-foot median divided freeways, the paved shoulder policy requires to widen the two shoulders from $6 \mathrm{ft}(1.88 \mathrm{~m})$ to $12 \mathrm{ft}$ (3.66-m) each, which reduce the width of ditch from $34 \mathrm{ft}(10.4 \mathrm{~m})$ to $22 \mathrm{ft}$ $(6.7 \mathrm{~m})$. For positive pavement drainage consideration, the median slopes should be changed to $4 \mathrm{H}: 1 \mathrm{~V}$ and even $2.5 \mathrm{H}: 1 \mathrm{~V}$ with the existence of superelevation. The $2.5 \mathrm{H}: 1 \mathrm{~V}$ and $4 \mathrm{H}: 1 \mathrm{~V}$ median slopes exceed the optimal $6 \mathrm{H}: 1 \mathrm{~V}$ slope for placing median barriers and cause practical concerns of the barrier's performance on such medians. As a practical solution, design engineers often place two lines of W-beam guardrail on the median shoulders (see Fig. 1a). While preventing cross-median crashes, the two lines of guardrail create great difficulty for vegetation maintenance operations (e.g. mowing). Thus there is a practical need to investigate the possibility of placing a single line of double-faced W-beam guardrail (see Fig. 1b) that is at least as safe as two lines of single-faced W-beam guardrails.

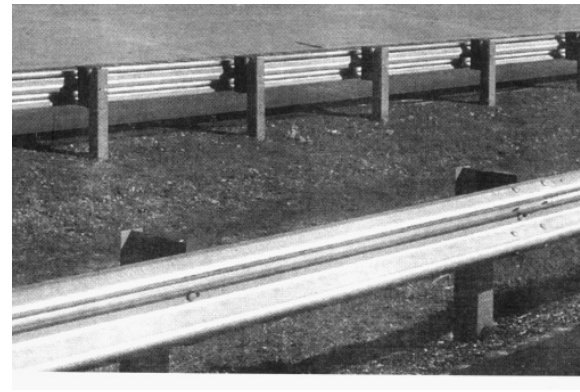

a. Two lines of single-faced W-beam

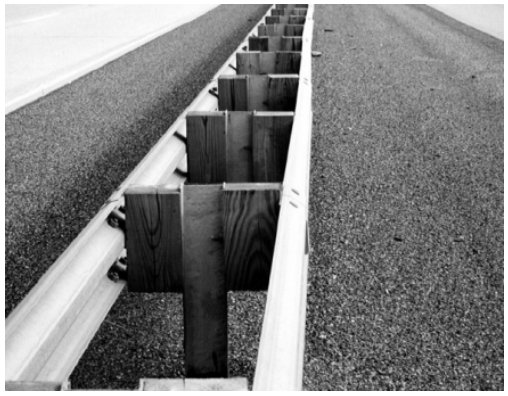

b. One line of double-faced W-beam

Figure 1: $\quad$ Single- and double-faced W-beam guardrails on six-lane freeways.

Figure 2 shows the placement of two lines of single-faced W-beam guardrails on a 46-foot (14-m) median of a six-lane freeway. Preliminary simulation results show that, after impacting one line of the single-faced W-beam, the vehicle did not reach and impact the other line from the backside. Therefore, only front-side impacts, as illustrated by the cases in Fig. 2, need to be performed on the singlefaced W-beam guardrails. In addition, since the $2.5 \mathrm{H}: 1 \mathrm{~V}$ slope (the high-side) represents a less favorable condition than the $4 \mathrm{H}: 1 \mathrm{~V}$ slope (the low-side), only simulations of vehicular impacts on the single-faced W-beam guardrail placed on the high-side of the median are performed. 


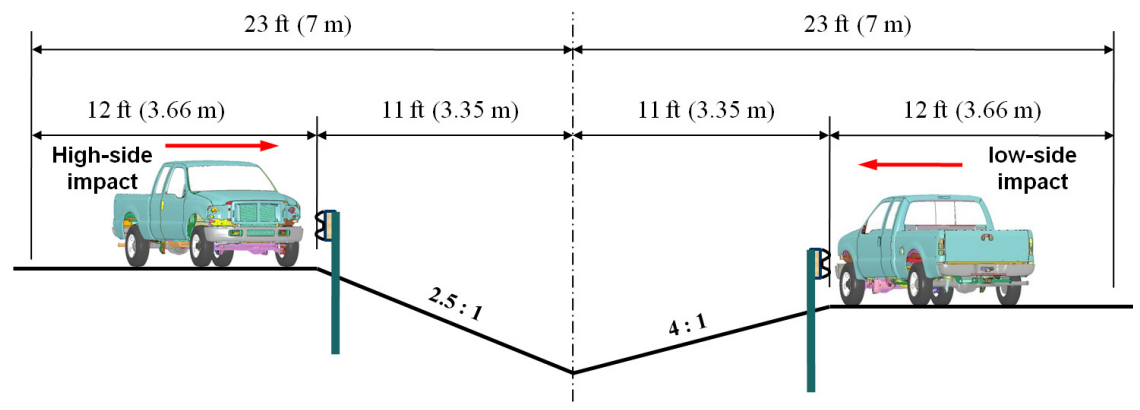

Figure 2: $\quad$ Vehicular impacts on single-faced W-beam guardrails.

Figure 3 shows the placement of a double-faced W-beam guardrail on the $2.5 \mathrm{H}: 1 \mathrm{~V}$ slope of a 46 -foot (14-m) median of a six-lane freeway. Vehicular impacts will be considered from both the backside (i.e., the guardrail side facing the ditch) and front-side (i.e., the guardrail side facing the travel lane).

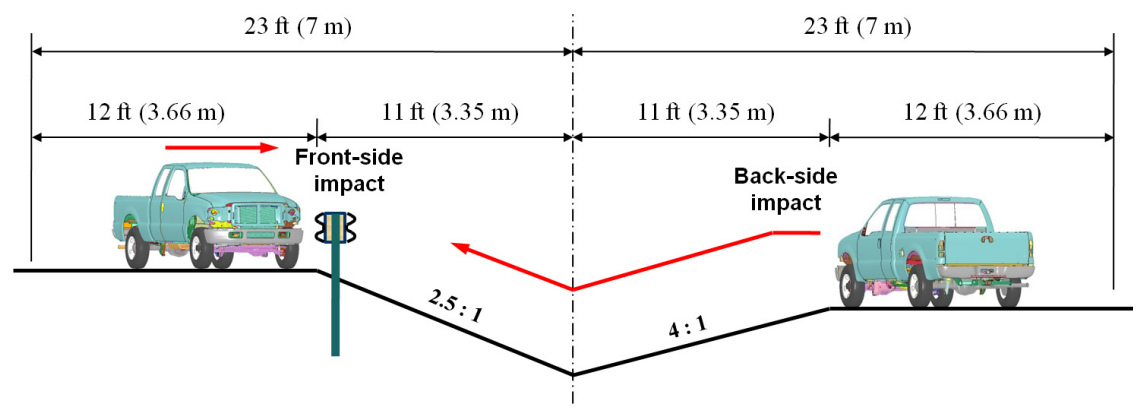

Figure 3: Vehicular impacts on a double-faced W-beam guardrail.

The standard impact condition of $62 \mathrm{mph}(100 \mathrm{~km} / \mathrm{hr})$ at $25^{\circ}$ specified by MASH is first used. FE simulations are then performed at higher impact speeds, 70 and $75 \mathrm{mph}$ (113 and $121 \mathrm{~km} / \mathrm{hr}$ ), and larger angles, $30^{\circ}$ and $35^{\circ}$. The simulation results of the single-faced $\mathrm{W}$-beam guardrail are used as a baseline to evaluate the performance of the double-faced guardrail.

\section{Finite element modelling}

The FE models used in this study include a Ford F250, a single-faced W-beam guardrail, a double-faced guardrail, and a 46-foot median. The vehicle model was obtained from the National Crash Analysis Centre (NCAC) and a number of modelling issues were corrected to ensure realistic vehicle dynamics as it crosses the ditch of the sloped median. These FE models are created for the commercial code, LS-DYNA [10], which is specifically developed for nonlinear transient analysis. 


\subsection{Vehicle model}

The vehicle model used in this study is a 2006 Ford F250 pickup truck that has a gross mass of 5,504 lb $(2,499 \mathrm{~kg})$. The FE model contains a total of 746 parts that are discretized into 737,990 nodes and 736,407 elements (25,905 solid, 2,305 beam, 707,656 shell, and 541 other elements). Eleven different constitutive models are used including the piecewise linear plasticity model defined for most steel components, the linear and nonlinear elastic spring model for the suspension springs, the viscous damping model for the shock absorbers, the lowdensity foam model for the radiator core, the spot-weld model for sheet metal connections, the viscous-elastic model for rubber cushions, and the null material model defined for 48 parts for contact purposes. Hourglass control is used on various components that could potentially experience large deformations.

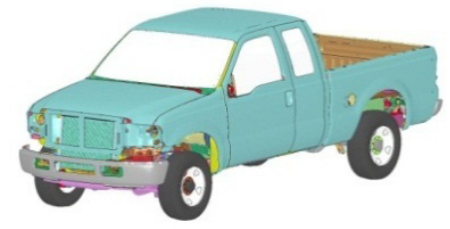

Figure 4: $\quad$ FE model of a 2006 Ford F250.

\subsection{W-beam guardrail model}

A W-beam guardrail is consisted of W-shaped rails spliced with rivets and attached by long bolts to steel posts supported by the indigenous soil (wood posts are used at the two terminals). A wood block (called a blockout) is placed between the rail and the steel posts. Figure 5 shows the FE models of the singlefaced and double-faced guardrails. Both guardrails have a length of $175 \mathrm{ft}(53 \mathrm{~m})$ and a rail height of 27 3/4 in $(0.7 \mathrm{~m})$ measured from rail top to the grade.

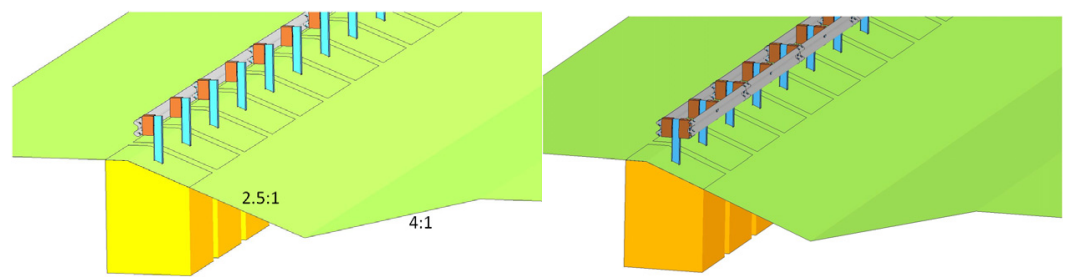

a. Single-faced W-beam guardrail

b. Double-faced W-beam guardrail

Figure 5: $\quad$ FE models of single- and double-faced W-beam guardrails.

The single-faced guardrail model contains a total of 712 parts that are discretized into 136,489 nodes and 133,121 elements (32,347 solid, 32 beam, 100,430 shell, and 312 other elements). The double-faced guardrail model has 1,036 parts that are discretized into 192,918 nodes and 184,079 elements (31,117 
solid, 32 beam, 152,330 shell, 186 spring, and 414 other elements). The FE models of the single-faced and double-faced guardrails have the same six material models including the piecewise linear plasticity model for the rails and the soil-and-foam model for the soil.

\subsection{Contact modelling}

The W-beam guardrails are semi-rigid barriers and may experience severe deformations under vehicular impacts. These deformations, along with the detailed parts and their connections, create significant challenges for contact modelling due to the complex geometries and the potential of edge contacts. Improper handling of contacts may result in unrealistic penetrations and subsequent numerical instabilities.

Figure 6 shows a portion of the W-beam model around a steel post where two pieces of rails are spliced using rivets and attached to the post by a long bolt. In addition to the contacts with the impacting vehicle, the contacts involving the rails, rivets, bolts, blockouts, posts, and soil are all considered. Edge contacts, e.g., the contacts between the rivets and the holes of the rails, are particularly difficult to handle, especially when the rails experience severe deformations. The automatic-general-interior contact algorithm in LS-DYNA is therefore utilized to account for both internal and external edge contacts of shell elements.

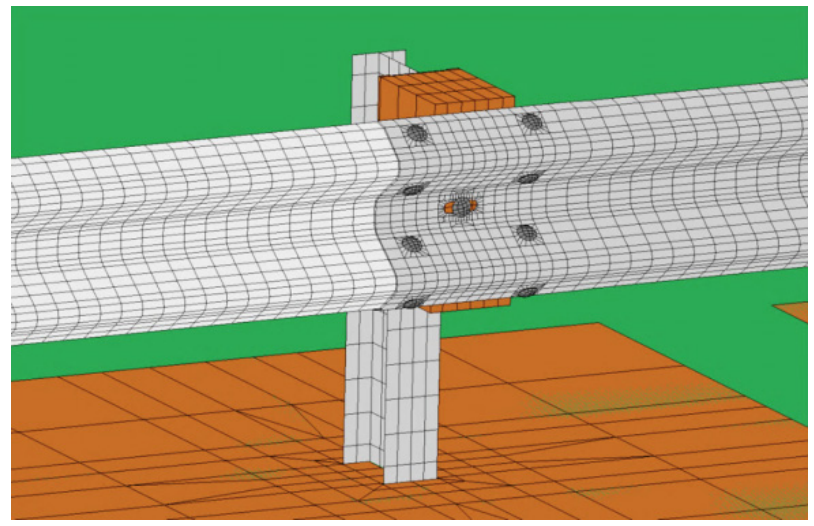

Figure 6: $\quad$ FE model of a guardrail around at a post.

\section{Simulation results and discussion}

\subsection{Simulation results of the single-faced $W$-beam guardrail}

All of the crash simulations are performed using LS-DYNA v971 running on a Linux cluster. The single-faced guardrail is evaluated at three impact speeds, i.e., 62, 70 and $75 \mathrm{mph}(100,113$ and $121 \mathrm{~km} / \mathrm{hr})$ and three impact angles, i.e., 25으. $30^{\circ}$, and $35^{\circ}$. The simulation results are summarized in Table 1. 
Table 1: $\quad$ Simulation results of the single-faced W-beam guardrail.

\begin{tabular}{|c|c|c|c|}
\hline \multirow{2}{*}{$\begin{array}{c}\text { Impact } \\
\text { angle }\end{array}$} & \multicolumn{3}{|c|}{ Impact speed } \\
\cline { 2 - 4 } $25^{\circ}$ & $\begin{array}{c}\text { Vehicle is redirected } \\
\text { on the shoulder }\end{array}$ & $\begin{array}{c}\text { Vehicle is redirected } \\
\text { but tends to rollover }\end{array}$ & $\begin{array}{c}\text { Vehicle is redirected } \\
\text { but tends to rollover }\end{array}$ \\
\hline $30^{\circ}$ & $\begin{array}{c}\text { Vehicle is redirected } \\
\text { but tends to rollover }\end{array}$ & $\begin{array}{c}\text { Vehicle rolls over } \\
\text { towards the ditch }\end{array}$ & $\begin{array}{c}\text { Vehicle rolls over } \\
\text { towards the ditch }\end{array}$ \\
\hline $35^{\circ}$ & $\begin{array}{c}\text { Vehicle is redirected } \\
\text { but tends to rollover }\end{array}$ & $\begin{array}{c}\text { Vehicle rolls over } \\
\text { towards the ditch }\end{array}$ & $\begin{array}{c}\text { Vehicle rolls over } \\
\text { towards the ditch }\end{array}$ \\
\hline
\end{tabular}

Under the $25^{\circ}$ impact at $62 \mathrm{mph}(100 \mathrm{~km} / \mathrm{hr})$, the single-faced guardrail is capable of redirecting the vehicle on the shoulder, satisfying the MASH Test Level 3 (TL-3) requirements. For $25^{\circ}$ impacts at higher speeds, however, the vehicle tends to rollover towards the ditch after being redirected. As the impact angle increases, the tendency of rollover increases and rollovers occur at impact speeds of70 mph (113 km/hr). It can be seen from the simulation results that rollover is more sensitive to impact angles than impact speeds. Figure 7 shows the vehicle response and a detailed account of vehicle-barrier interactions for the $25^{\circ}$ impact at $62 \mathrm{mph}(100 \mathrm{~km} / \mathrm{hr})$. Figure 8 shows the results for the $35^{\circ}$ impact at $75 \mathrm{mph}(121 \mathrm{~km} / \mathrm{hr})$.

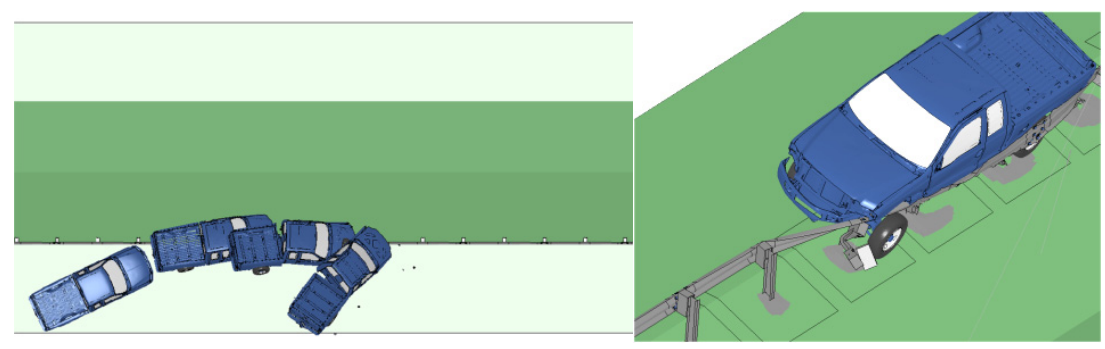

Figure 7: Vehicle response (left) and vehicle-barrier interaction (right) for the single-faced guardrail under $25^{\circ}$ impact at $62 \mathrm{mph}(100 \mathrm{~km} / \mathrm{hr})$.

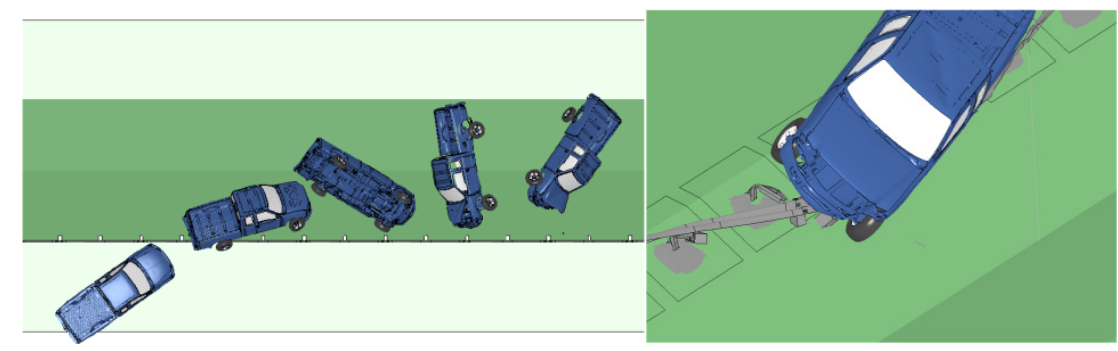

Figure 8: Vehicle response (left) and vehicle-barrier interaction (right) for the single-faced guardrail under $35^{\circ}$ impact at $75 \mathrm{mph}(121 \mathrm{~km} / \mathrm{hr})$. 


\subsection{Simulation results of the double-faced $\mathrm{W}$-beam guardrail}

For the double-faced guardrail, the same impact speeds and impact angles as those for the single-faced guardrail are used in the simulations. Unlike the singlefaced guardrail, the double-faced guardrail is evaluated for both front-side and backside impacts, with the results given in Tables 2 and 3, respectively.

Table 2: Simulation results of front-side impacts on the double-faced Wbeam guardrail.

\begin{tabular}{|c|c|c|c|}
\hline \multirow{2}{*}{$\begin{array}{c}\text { Impact } \\
\text { angle }\end{array}$} & \multicolumn{3}{|c|}{ Impact speed } \\
\cline { 2 - 4 } $25^{\circ}$ & $\begin{array}{c}\text { Vehicle is redirected } \\
\text { on the shoulder }\end{array}$ & $\begin{array}{c}\text { Vehicle is redirected } \\
\text { on the shoulder }\end{array}$ & $\begin{array}{c}\text { Vehicle is redirected } \\
\text { on the shoulder }\end{array}$ \\
\hline $30^{\circ}$ & $\begin{array}{c}\text { Vehicle is redirected } \\
\text { but tends to roll over }\end{array}$ & $\begin{array}{c}\text { Vehicle is redirected } \\
\text { followed by a rollover }\end{array}$ & $\begin{array}{c}\text { Vehicle is redirected } \\
\text { followed by a rollover }\end{array}$ \\
\hline $35^{\circ}$ & $\begin{array}{c}\text { Vehicle is redirected } \\
\text { followed by a rollover }\end{array}$ & $\begin{array}{c}\text { Vehicle rolls over } \\
\text { towards the ditch }\end{array}$ & $\begin{array}{c}\text { Vehicle rolls over } \\
\text { towards the ditch }\end{array}$ \\
\hline
\end{tabular}

Table 3: Simulation results of backside impacts on the double-faced Wbeam guardrail.

\begin{tabular}{|c|c|c|c|}
\hline \multirow{2}{*}{$\begin{array}{c}\text { Impact } \\
\text { angle }\end{array}$} & \multicolumn{3}{|c|}{ Impact speed } \\
\cline { 2 - 4 } & $62 \mathrm{mph}(100 \mathrm{~km} / \mathrm{hr})$ & $70 \mathrm{mph}(113 \mathrm{~km} / \mathrm{hr})$ & $75 \mathrm{mph}(121 \mathrm{~km} / \mathrm{hr})$ \\
\hline $25^{\circ}$ & $\begin{array}{c}\text { Vehicle is retained in } \\
\text { the ditch }\end{array}$ & $\begin{array}{c}\text { Vehicle is retained in } \\
\text { the ditch }\end{array}$ & $\begin{array}{c}\text { Vehicle is retained in } \\
\text { the ditch }\end{array}$ \\
\hline $30^{\circ}$ & $\begin{array}{c}\text { Vehicle is retained in } \\
\text { the ditch }\end{array}$ & $\begin{array}{c}\text { Vehicle is retained in } \\
\text { the ditch }\end{array}$ & $\begin{array}{c}\text { Vehicle is retained in } \\
\text { the ditch }\end{array}$ \\
\hline $35^{\circ}$ & $\begin{array}{c}\text { Vehicle is retained in } \\
\text { the ditch }\end{array}$ & $\begin{array}{c}\text { Vehicle is retained in } \\
\text { the ditch }\end{array}$ & $\begin{array}{c}\text { Vehicle is retained in } \\
\text { the ditch }\end{array}$ \\
\hline
\end{tabular}

In front-side impacts, the double-faced guardrail generally performs better than the single-faced guardrail at the $25^{\circ}$ impact angle. For example, in all three $25^{\circ}$ impacts on the double-faced guardrail, the vehicle does not rollover or tend to rollover after being redirected. For the cases of the single-faced guardrail, the vehicle tends to roll over in $25^{\circ}$ impacts at 70 and $75 \mathrm{mph}(113$ and $121 \mathrm{~km} / \mathrm{hr}$ ). The added backside rail increases the stiffness and strength of the guardrail which in turn helps redirect the vehicle and reduce the tendency of vehicle rollover. Figure 9 shows the vehicle responses and a detailed account of vehiclebarrier interaction for the $25^{\circ}$ front-side impact at $75 \mathrm{mph}(121 \mathrm{~km} / \mathrm{hr})$.

For all backside impacts, the double-faced guardrail is capable of retaining the vehicle within the ditch. The vehicle is also redirected in all of these cases except for the $30^{\circ}$ impact at $62 \mathrm{mph}(100 \mathrm{~km} / \mathrm{hr})$, in which the vehicle locks with the post upon impact and is therefore not redirected. In the most severe case of 
impact, i.e., at $35^{\circ}$ and $75 \mathrm{mph}(121 \mathrm{~km} / \mathrm{hr})$, the vehicle is redirected and retained on the slope, as shown in Figure 10. In general, the double-faced guardrail is shown to have at least the same performance as the single-faced guardrail.

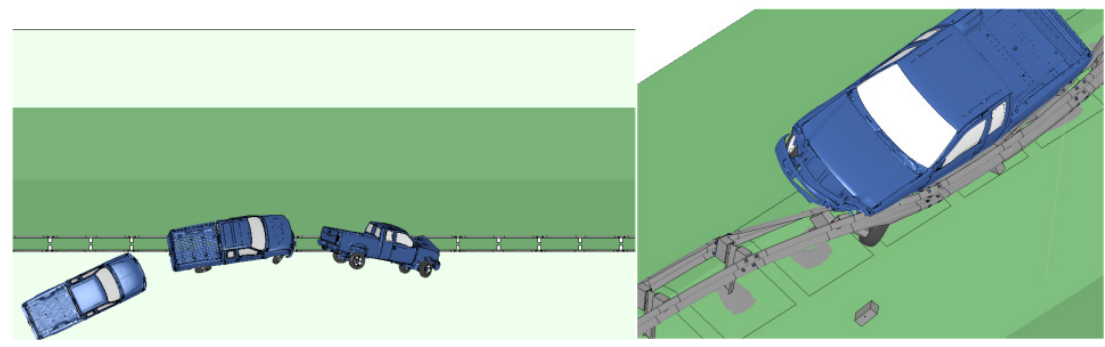

Figure 9: Vehicle response (left) and vehicle-barrier interaction (right) for the double-faced guardrail under $25^{\circ}$ front-side impact at $75 \mathrm{mph}$.

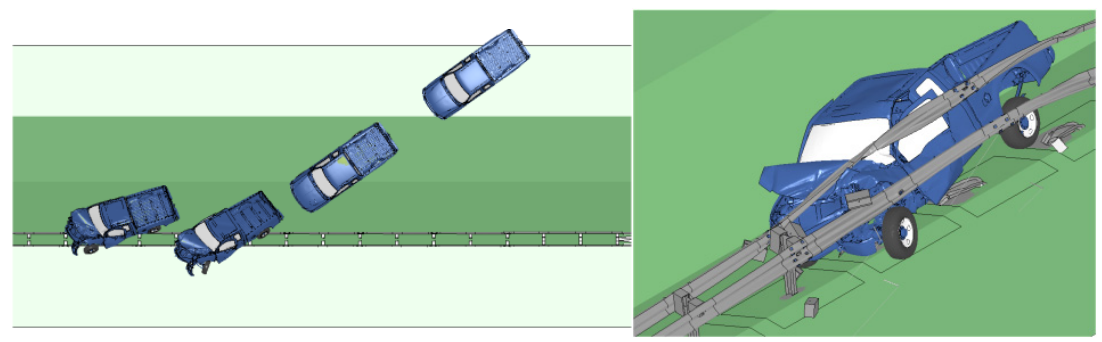

Figure 10: Vehicle response (left) and vehicle-barrier interaction (right) for the double-faced guardrail under $35^{\circ}$ backside impact at $75 \mathrm{mph}$.

\subsection{Simulation results of a new double-faced $W$-beam guardrail}

A concern about the performance of the double-faced guardrail is the potential of small passenger cars penetrating under the guardrail in backside impacts, since these vehicles have lower profiles than the Ford F250. To address this concern, a new design of the double-faced guardrail is proposed, as shown in Figure 11.

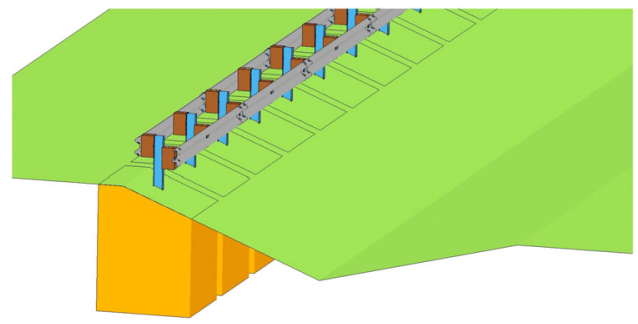

Figure 11: $\quad$ FE model of a new double-faced W-beam guardrail. 
In the new double-faced guardrail, the backside rail is lowered by 7.1 in $(0.18 \mathrm{~m})$ from its original location in the original design. The new double-faced guardrail is evaluated under impacts of the Ford F250 to ensure it has the same performance as the original design. The simulation results of front-side and backside impacts are summarized in Tables 4 and 5, respectively.

Table 4: Simulation results of front-side impacts on the new double-faced W-beam guardrail.

\begin{tabular}{|c|c|c|c|}
\hline \multirow{2}{*}{$\begin{array}{c}\text { Impact } \\
\text { angle }\end{array}$} & \multicolumn{3}{|c|}{ Impact speed } \\
\cline { 2 - 4 } & $62 \mathrm{mph}(100 \mathrm{~km} / \mathrm{hr})$ & $70 \mathrm{mph}(113 \mathrm{~km} / \mathrm{hr})$ & $75 \mathrm{mph}(121 \mathrm{~km} / \mathrm{hr})$ \\
\hline $25^{\circ}$ & $\begin{array}{c}\text { Vehicle is redirected } \\
\text { on the shoulder }\end{array}$ & $\begin{array}{c}\text { Vehicle is redirected } \\
\text { on the shoulder }\end{array}$ & $\begin{array}{c}\text { Vehicle is redirected } \\
\text { on the shoulder }\end{array}$ \\
\hline $30^{\circ}$ & $\begin{array}{c}\text { Vehicle is redirected } \\
\text { on the shoulder }\end{array}$ & $\begin{array}{c}\text { Vehicle is redirected } \\
\text { followed by a rollover }\end{array}$ & $\begin{array}{c}\text { Vehicle is redirected } \\
\text { followed by a rollover }\end{array}$ \\
\hline $35^{\circ}$ & $\begin{array}{c}\text { Vehicle rolls over } \\
\text { towards the ditch }\end{array}$ & $\begin{array}{c}\text { Vehicle rolls over } \\
\text { towards the ditch }\end{array}$ & $\begin{array}{c}\text { Vehicle rolls over } \\
\text { towards the ditch }\end{array}$ \\
\hline
\end{tabular}

Table 5: $\quad$ Simulation results of backside impacts on the new double-faced Wbeam guardrail.

\begin{tabular}{|c|c|c|c|}
\hline \multirow{2}{*}{$\begin{array}{c}\text { Impact } \\
\text { angle }\end{array}$} & \multicolumn{3}{|c|}{ Impact speed } \\
\cline { 2 - 4 } & $62 \mathrm{mph}(100 \mathrm{~km} / \mathrm{hr})$ & $70 \mathrm{mph}(113 \mathrm{~km} / \mathrm{hr})$ & $75 \mathrm{mph}(121 \mathrm{~km} / \mathrm{hr})$ \\
\hline $25^{\circ}$ & $\begin{array}{c}\text { Vehicle is retained in } \\
\text { the ditch }\end{array}$ & $\begin{array}{c}\text { Vehicle is retained in } \\
\text { the ditch }\end{array}$ & $\begin{array}{c}\text { Vehicle is retained in } \\
\text { the ditch }\end{array}$ \\
\hline $30^{\circ}$ & $\begin{array}{c}\text { Vehicle is retained in } \\
\text { the ditch }\end{array}$ & $\begin{array}{c}\text { Vehicle is retained in } \\
\text { the ditch }\end{array}$ & $\begin{array}{c}\text { Vehicle is retained in } \\
\text { the ditch }\end{array}$ \\
\hline $35^{\circ}$ & $\begin{array}{c}\text { Vehicle is retained in } \\
\text { the ditch }\end{array}$ & $\begin{array}{c}\text { Vehicle is retained in } \\
\text { the ditch }\end{array}$ & $\begin{array}{c}\text { Vehicle is retained in } \\
\text { the ditch }\end{array}$ \\
\hline
\end{tabular}

The simulation results show that the new double-faced guardrail has a similar performance to the original design under both front-side and backside impacts. For front-side impacts, the lowered backside rail does not degrade the overall performance of the double-faced guardrail. This is observed from the simulation results for all impact angles and impact speeds. For backside impacts, the new double-faced guardrail has more interaction with the vehicle due to the lowered backside rail, and thus performs more effectively than the original design. Consequently, the vehicle's response in backside impacts, i.e., vehicle rotations, appears to be less severe than that in the original design.

Figure 12 shows the vehicle response and a detailed account of vehicle-barrier interaction for the $25^{\circ}$ front-side impact at $75 \mathrm{mph}(121 \mathrm{~km} / \mathrm{hr})$ on the new double-faced guardrail. Figure 13 shows the results for the $35^{\circ}$ backside impact at $75 \mathrm{mph}(121 \mathrm{~km} / \mathrm{hr})$. Comparing to the vehicle's response shown in Figures 9 and 10 , it is observed that the new and original double-faced guardrails have similar performance. 


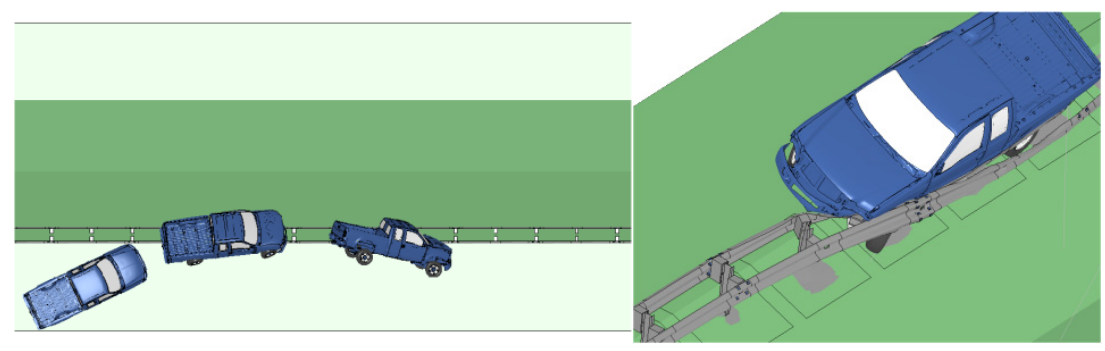

Figure 12: Vehicle response (left) and vehicle-barrier interaction (right) for the new double-faced guardrail under $25^{\circ}$ front-side impact at $75 \mathrm{mph}$.

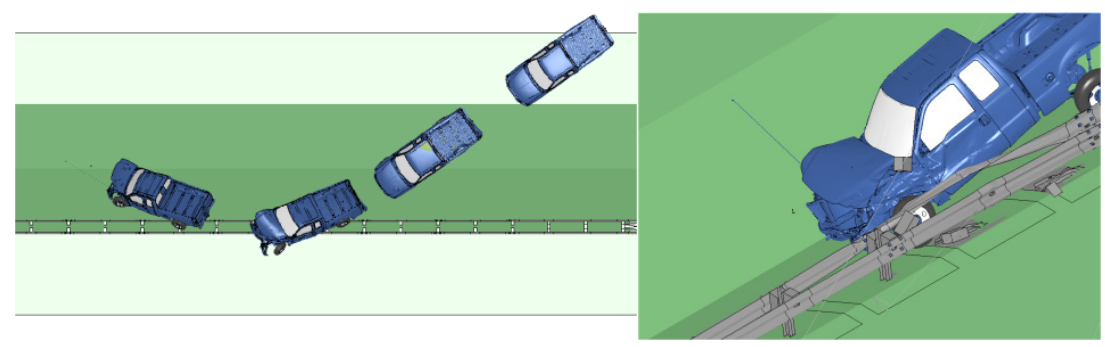

Figure 13: Vehicle response (left) and vehicle-barrier interaction (right) for the new double-faced guardrail under $35^{\circ}$ backside impact at $75 \mathrm{mph}$.

\section{Conclusions}

In this paper, finite element simulations are performed to study the performance of a single-faced W-beam guardrail and two designs of double-faced guardrails under impacts of a 2006 Ford F250 pickup truck. The simulation results provide significant insight into the crash mechanisms of vehicular impacts on W-beam guardrails. The single-faced guardrail performs effectively under a vehicular impact at $25^{\circ}$ and $62 \mathrm{mph}(100 \mathrm{~km} / \mathrm{hr})$, which is the standard Test Level 3 (TL-3) condition specified in MASH. The single-faced guardrail in this study is on the border between the ditch slope and its adjacent shoulder, which represents a more severe test condition than the flat terrain used in all tests specified by MASH. In addition, the 2006 Ford F250 has a larger mass and size than the TL-3 vehicle, and thus increases the intensity of the crashes. Given these factors, the single-faced guardrail can be said to outperform the TL-3 requirements. Under impacts at larger speeds and/or angles, the vehicle is found to either roll over or exhibit a strong tendency to rollover towards the ditch.

The two double-faced guardrails have similar performance to the single-faced guardrail in a front-side impact under the standard TL-3 impact speed and angle, i.e., $62 \mathrm{mph}(100 \mathrm{~km} / \mathrm{hr})$ and $25^{\circ}$. In all other front-side impacts, the doublefaced guardrail is found to reduce the tendency of vehicle rollover compared to the single-faced guardrail. For backside impacts, both double-faced guardrails 
perform better than in front-side impacts. The vehicle is successfully retained in the ditch without rollover or the tendency to rollover for all backside impacts. If the double-faced guardrail were to replace the two lines of single-faced guardrail, the large number of vehicle rollovers occurring with the single-faced guardrail could be prevented, even at large impact speeds and/or angles.

It is also observed that there is no significant performance difference between the two designs of the double-faced guardrails under the impacts of a Ford F250; this is true for both front-side and backside impacts. However, the new doublefaced guardrail is expected to perform better than the original design in backside impacts by small vehicles such as passenger cars. It is noted that the simulation results of this project can be used to interpret the performance trends of W-beam guardrails, but they should not be used to draw definitive conclusions about guardrail performance for a specific crash event, because many factors that could affect guardrail performance are not considered in this study.

\section{References}

[1] BMI-SG, Improved Guidelines for Median Safety. NCHRP 17-14(2) Draft Report of Analysis Findings, Transportation Research Board, National Research Council, Vienne, VA, 2004.

[2] Ross Jr., H.E. and Sicking, D.L., Guidelines for placement of longitudinal barriers on slopes. Transportation Research Record, 970, pp. 3-9, 1984.

[3] AASHTO, 2006 Roadside Design Guide, $3^{\text {rd }}$ ed. American Association of State Highway and Transportation Officials, Washington, D.C., 2006.

[4] MASH, Manual for Assessing Safety Hardware. American Association of State and Highway Transportation Officials, Washington, D.C., 2009.

[5] Ross Jr., H.E., Sicking, D.L., Zimmer, R.A., and Michie, J.D., Recommended Procedures for the Safety Performance Evaluation of Highway Features, NCHRP Report 350. Transportation Research Board, National Research Council, Washington D.C., 1993.

[6] Zaouk, A.K., Marzougui, D., and Bedewi, N.E., Development of a detailed vehicle finite element model, Part I: methodology. International Journal of Crashworthiness, 5(1), pp. 25-36, 2000.

[7] Zaouk, A.K., Marzougui, D., and Kan, C.D., Development of a detailed vehicle finite element model, Part II: material characterization and component testing. International Journal of Crashworthiness, 5(1), pp. 3750, 2000.

[8] Mohan, P., Marzougui, D., Meczkowski, L., and Bedewi, N.E., Finite element modeling and validation of a 3-strand cable guardrail system. International Journal of Crashworthiness, 10, pp. 267-273, 2005.

[9] Mohan, P., Marzougui, D., and Kan, C.D., Validation of a single unit truck model for roadside hardware impact. International Journal of Vehicle Systems Modelling and Testing, 2(1), pp. 1-15, 2007.

[10] LSTC, LS-DYNA Keyword User's Manual, v971. Livermore Software Technology Corporation, Livermore, CA, May 2007. 